\title{
Effects of delta-opioid receptor agonist pretreatment on the cardiotoxicity of bupivacaine in rats
}

\author{
Chenran Wang ${ }^{1}$, Shen Sun ${ }^{1}$, Jing Jiao ${ }^{1}$, Xinhua Y ${ }^{2}$ and Shaoqiang Huang ${ }^{1 *}$
}

\begin{abstract}
Background: Delta-opioid receptor is widely expressed in human and rodent hearts, and has been proved to protect cardiomyocytes against ischemia/reperfusion and heart failure. The antagonist of delta-opioid receptor could block the rescue effect of lipid emulsion against local anesthetic cardiotoxicity. However, no evidence is available for the direct effect of delta-opioid-receptor agonists on the cardiotoxicity of local anesthetics.

Methods: Anesthetized Sprague Dawley rats were divided into five groups. Group NS received $2 \mathrm{ml} \cdot \mathrm{kg}^{-1} \cdot \mathrm{min}^{-1}$ normal saline, group LE received $2 \mathrm{ml} \cdot \mathrm{kg}^{-1} \cdot \mathrm{min}^{-1} 30 \%$ lipid emulsion and group BW received $0.1,1.0$, or $5.0 \mathrm{mg} / \mathrm{kg}$ BW373U86, a delta-opioid-receptor agonist, for $5 \mathrm{~min}$. Then $0.5 \%$ bupivacaine was infused intravenously at a rate of $3.0 \mathrm{mg} \cdot \mathrm{kg}^{-1} \cdot \mathrm{min}^{-1}$ until asystole. The time of arrhythmia, 50\% mean arterial pressure-, $50 \%$ heart rate-reduction and asystole were recorded, and the dose of bupivacaine at each time point was calculated.
\end{abstract}

Results: All three different doses of BW373U86 did not affect the arrhythmia, 50\% mean arterial pressure-reduction, $50 \%$ heart rate-reduction and asystole dose of bupivacaine compared with group NS. 30\% LE significantly increased the bupivacaine threshold of 50\% mean arterial pressure-reduction (17.9 [15.4-20.7] versus 7.2 [5.9-8.7], $p=0.018$ ), $50 \%$ heart rate-reduction $(18.7 \pm 4.2$ versus $8.8 \pm 1.7, p<0.001)$ and asystole (26.5 [21.0-29.1] versus 11.3 [10.7-13.4], $p=0.008)$ compared with group NS. There was no difference between group LE and group NS in the arrhythmia dose of bupivacaine (9.9 [8.9-11.7] versus $5.6[4.5-7.0], p=0.060)$.

Conclusions: Our data show that BW373U86 does not affect the cardiotoxicity of bupivacaine compared with NS control in rats. 30\% LE pretreatment protects the myocardium against bupivacaine-induced cardiotoxicity.

Keywords: Bupivacaine, Cardiotoxicity, Delta-opioid receptor (DOR), BW373U86, Local anesthetic systemic toxicity (LAST)

\section{Background}

With the development of enhanced recovery after surgery (ERAS) and labor analgesia, peripheral nerve block and epidural anesthesia become more and more important for their indispensable role in comfort medicine. Local anesthetic systemic toxicity (LAST) is the adverse effect

*Correspondence: drhuangsq@163.com

1 Department of Anesthesia, Obstetrics \& Gynecology Hospital of Fudan University, Shanghai, China

Full list of author information is available at the end of the article of regional anesthesia due to unexpected local anesthetics absorbed or infused into the bloodstream [1]. The main symptoms of LAST are central nervous systemic toxicity and cardiotoxicity, of which cardiotoxicity is lifethreatening [2]. Lipid emulsion (LE) has been reported to resuscitate LAST successfully in animal experiments and clinical practices $[3,4]$. A widely accepted theory of LE rescue is that lipophilic local anesthetics are absorbed into the lipid phase of plasma from tissues [5]. Thus, the toxicity of local anesthetics to tissue is mitigated by LE. However, in 2015, Partownavid et al. [6] reported that LE original author(s) and the source, provide a link to the Creative Commons licence, and indicate if changes were made. The images or other third party material in this article are included in the article's Creative Commons licence, unless indicated otherwise in a credit line to the material. If material is not included in the article's Creative Commons licence and your intended use is not permitted by statutory regulation or exceeds the permitted use, you will need to obtain permission directly from the copyright holder. To view a copy of this licence, visit http://creativecommons.org/licenses/by/4.0/. The Creative Commons Public Domain Dedication waiver (http://creativeco mmons.org/publicdomain/zero/1.0/) applies to the data made available in this article, unless otherwise stated in a credit line to the data. 
fails to rescue rats against bupivacaine-induced cardiotoxicity when a high-dose of delta-opioid receptor (DOR) antagonist was preconditioned. This indicates that DOR is involved in the LE rescue of LAST.

DOR is widely expressed in human and rodent cardiomyocytes. And the expression of DOR increases in response to heart failure, hypoxia, aging, and other physical or pathological stimuli [7]. Many studies have proved that agonists of DOR can protect the myocardium against ischemia/reperfusion and heart failure [8-11]. However, no evidence is available concerning the direct effect of DOR agonists on the cardiotoxicity of local anesthetics.

We hypothesized that the agonist of DOR can protect the heart against bupivacaine-induced cardiotoxicity in rats. The purpose of this study is to investigate whether DOR agonist has protective effects on bupivacaine cardiotoxicity. We pretreated anesthetized Sprague Dawley rats with normal saline, lipid emulsion, and three different doses of BW373U86 (0.1, 1.0, $5.0 \mathrm{mg} / \mathrm{kg})$, a DOR agonist, before bupivacaine infusion. Our primary outcome is the asystole dose of bupivacaine in rats. Our secondary outcomes are the doses of bupivacaine when arrhythmia, $50 \%$ mean arterial pressure (MAP)-reduction, and 50\% heart rate (HR)-reduction occur.

\section{Methods}

\section{Animals}

The animal study was reviewed and approved by the Animal Care and Use Committee of Fudan University on 16 March 2021 (ethic approval ID: 20,210,316-001) and performed according to the National Institutes of Health Guide for the Care and Use of Laboratory Animals. All animal experiments were reported in compliance with the ARRIVE guidelines. Thirty male Sprague Dawley rats aged 5-6 weeks were purchased from Shanghai JieSiJie Laboratory Animals Co. Ltd (Shanghai, China) and housed in a standard environment $\left(23 \pm 1^{\circ} \mathrm{C}, 50 \%\right.$ relative humidity and 12-h day/night cycle) for more than 7 days before experiments.

\section{Anesthesia and Monitoring}

This model of LAST has been used by many previous studies $[2,4,6]$. Rats $(240-280 \mathrm{~g})$ fasted for $12 \mathrm{~h}$ before experiments with free access to water. The animals were anesthetized with $350 \mathrm{mg} / \mathrm{kg}$ chloral hydrate intraperitoneally. Then they were nasally ventilated using a rodent animal ventilator (ALC-V8, Shanghai Alcott biotech CO.LTD, Shanghai, China). The ventilator settings are as follows: respiratory rate 60 breaths/min, tidal volume $2 \mathrm{ml} / 100 \mathrm{~g}$, and inspiratory to expiratory ratio 1:2. Sevoflurane $(1-2 \%)$ in $30 \% \mathrm{O}_{2}$ was started before the median incision in the neck was made [12]. The right jugular vein and the left carotid artery were intubated with a silastic tube (external diameter $\times$ internal diameter $=1.0 \times 0.5 \mathrm{~mm}$ ). Then, rats were intubated by tracheotomy with a $16 \mathrm{G}$ angio-catheter. Last, three electrode needles were inserted subcutaneously in both forelimbs and left hindlimb to measure Electrocardiogram (ECG). ECG and invasive arterial blood pressure were constantly recorded with a monitor. After all invasive procedures were finished, sevoflurane was discontinued, the time of surgery (time from neck incision to the end of invasive procedures) was recorded. Rats were allowed to stabilize for $10-15 \mathrm{~min}$. At the end of the stabilization period, HR and MAP were recorded as baseline values. Rectal temperature was maintained at $37 \pm 1^{\circ} \mathrm{C}$ by a heater throughout the experiment.

\section{Experimental Procedures}

Thirty rats were randomly assigned to five groups $(n=6$ for each) according to random numbers. All liquids were infused through the right jugular vein using an infusion pump (B. Braun Medical Co., Ltd, Suzhou, China). Group NS received $2 \mathrm{ml} \cdot \mathrm{kg}^{-1} \cdot \mathrm{min}^{-1}$ normal saline for $5 \mathrm{~min}$; group LE received $2 \mathrm{ml} \cdot \mathrm{kg}^{-1} \cdot \mathrm{min}^{-1} 30 \%$ lipid emulsion (80PE018, Sino-Swed Pharmaceutical Corp. Ltd, Jiangsu, China) for $5 \mathrm{~min}$; and BW groups received 0.1, 1.0 or $5.0 \mathrm{mg} / \mathrm{kg}$ (diluted in $10 \mathrm{ml} / \mathrm{kg}$ normal saline) BW373U86 (Cat. No. 1663, Tocris Bioscience, USA) for $5 \mathrm{~min}$. The low, median and high doses of BW373U86 were set as $0.1,1.0$, and $5.0 \mathrm{mg} / \mathrm{kg}$ according to the previous study [13-16]. After a 1-min wait, which was the time of changing syringes and resetting the velocity of the infusion pump, $0.5 \%$ bupivacaine $(090,809$, Shanghai Harvest Pharmaceutical CO., LTD, Shanghai, China) at a rate of $3.0 \mathrm{mg} \cdot \mathrm{kg}^{-1} \cdot \mathrm{min}^{-1}$ was started to infuse until asystole occurs. Rats were anesthetized with $350 \mathrm{mg} / \mathrm{kg}$ chloral hydrate. Thus, animals went into cardiac arrest gradually under anesthesia at the end of the study.

The following toxic endpoints were recorded by an observer unaware of the grouping, and the doses of bupivacaine at each endpoint were calculated: the first arrhythmia, defined as the appearance of cardiac rhythm disturbance on the ECG accompanied by an abnormal pulsation on the arterial pressure trace; 50\% MAP-reduction, defined as the MAP of $50 \%$ baseline value; $50 \%$ HR-reduction, defined as the HR of $50 \%$ baseline value; and asystole, defined as the lack of recognizable beat on the ECG for $10 \mathrm{~s}$ after the appearance of the last systole. These observed indexes were decided following previous studies $[4,9,17]$.

\section{Statistical Analysis}

The software program of Power and Sample Size (PASS15.0.5, NCSS Inc, Kaysville, UT) was used to calculate the sample size [2]. Based on the 


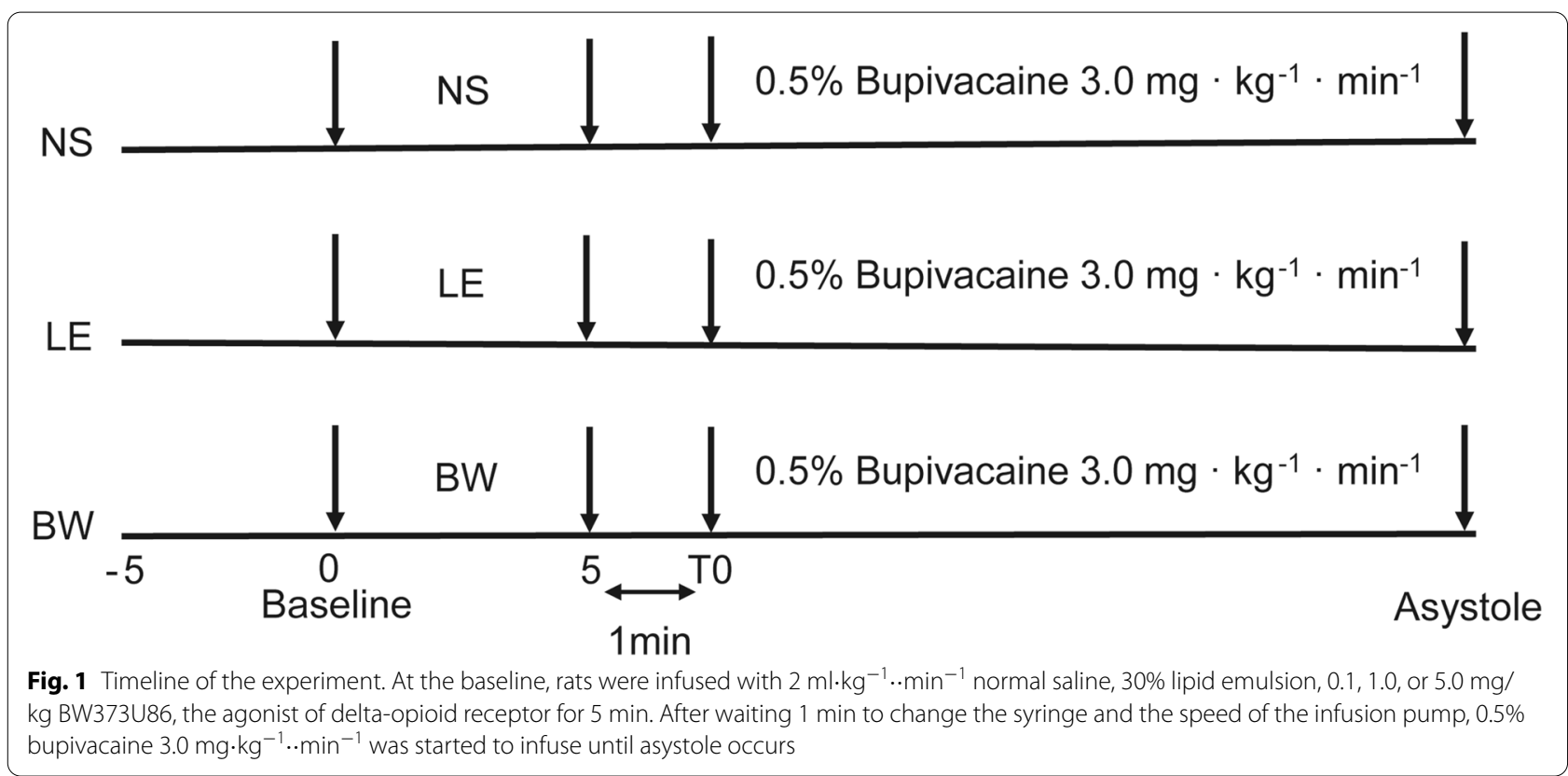

preliminary experiments of $0.5 \%$ bupivacaine at a rate of $3.0 \mathrm{mg} \cdot \mathrm{kg}^{-1} \cdot \mathrm{min}^{-1}$. The mean asystole doses of group NS, LE, $0.1,1.0$, and $5.0 \mathrm{mg} / \mathrm{kg}$ BW are 12.125 .514 .4 13.2 12.9, and the standard errors are 2.3 5.0 3.1 4.0 4.0 respectively. Power was set at 0.90 ; significance was set at 0.05 , and one-way analysis of variance (ANOVA) was used. The effect size of 5 was estimated. Considering the loss potential and errors, 6 rats for each group were decided.

Data were analyzed with SPSS (version 20.0; Chicago, Illinois, USA) for Windows by a statistician who is blinded to the grouping. The Shapiro-Wilk test was used to test for normal distribution. Normal-distributed measures and abnormal-distributed measures were presented as mean \pm standard deviation and median [interquartile range] respectively. Normally distributed measures were compared using a one-way ANOVA model and abnormally distributed measures were compared using the Kruskal-Wallis test. The individual pairwise mean comparisons were adjusted with the Tukey studentized range criterion or Dunn's test to account for multiple comparisons. The family-wise significance for all tests is set at $p<0.05$.

\section{Results}

The timeline of the experiment is shown in Fig. 1. The baseline values of weight, MAP, HR and invasive surgery time are presented in Table 1, and no difference was observed among these five groups.

All three doses of BW373U86 (0.1, 1.0, and $5.0 \mathrm{mg} / \mathrm{kg})$ had no effect on the bupivacaine threshold of arrhythmia, 50\% MAP-reduction, 50\% HR-reduction, or asystole compared with NS control (Fig. 2). 30\% LE increased the bupivacaine threshold of 50\% MAP-reduction (17.9 [15.4-20.7] versus 7.2 [5.9-8.7], $p=0.018), 50 \% \mathrm{HR}-$ reduction $(18.7 \pm 4.2$ versus $8.8 \pm 1.7, p<0.001)$ and asystole (26.5 [21.0-29.1] versus 11.3 [10.7-13.4], $p=0.008)$ compared with group NS. There is no difference between

Table 1 Baseline values

\begin{tabular}{lccccc}
\hline & NS & LE & $\mathbf{0 . 1}$ BW & 1.0 BW & 5.0 BW \\
\hline Weight (g) & $262.8 \pm 11.9$ & $262.2 \pm 9.0$ & $263.7 \pm 9.0$ & $263.7 \pm 6.5$ & $262.0 \pm 6.5$ \\
MAP & $78.8 \pm 9.9$ & $77.7 \pm 10.1$ & $87.5 \pm 4.5$ & $77.0 \pm 5.7$ & $89.2 \pm 14.5$ \\
(mmHg) & $221.6 \pm 32.2$ & $225.0 \pm 42.2$ & $221.5 \pm 20.3$ & $227.3 \pm 39.7$ & $217.8 \pm 28.5$ \\
HR (beats/min) & $14.6 \pm 1.1$ & $13.0 \pm 1.5$ & $13.0 \pm 2.0$ & $14.0 \pm 0.6$ & $13.8 \pm 1.9$ \\
Surgery time (min) & &
\end{tabular}

Table 1 Baseline values. Values are presented as mean \pm standard deviation, $n=6$ for each group. There was no difference in baseline values among NS, LE, $0.1,1.0$, and 5.0 BW groups. Abbreviations: NS normal saline, LE lipid emulsion, BW BW373U86, the agonist of delta-opioid receptor, MAP mean arterial pressure, $H R$ heart rate. Surgery time: time from neck incision to the end of all invasive procedures 
(a) Arrhythmia

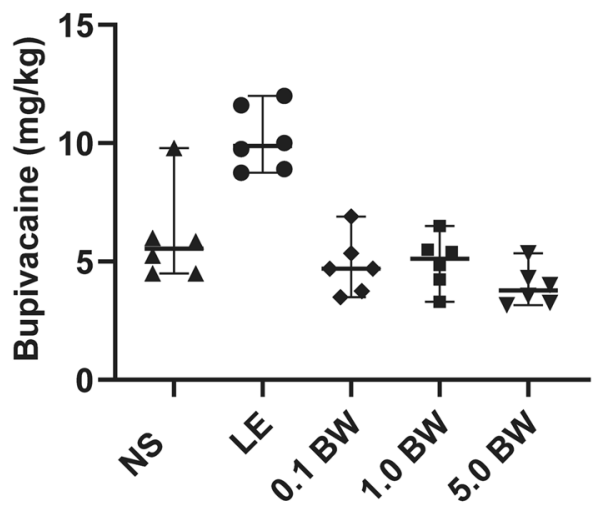

(c) $50 \% \mathrm{HR}$ reduction

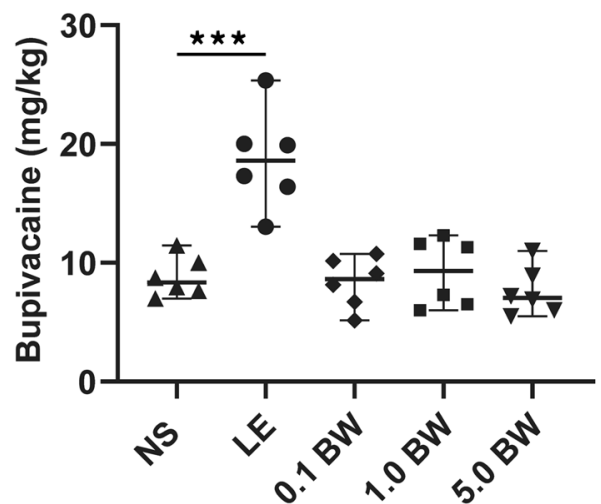

(b) $50 \%$ MAP-reduction

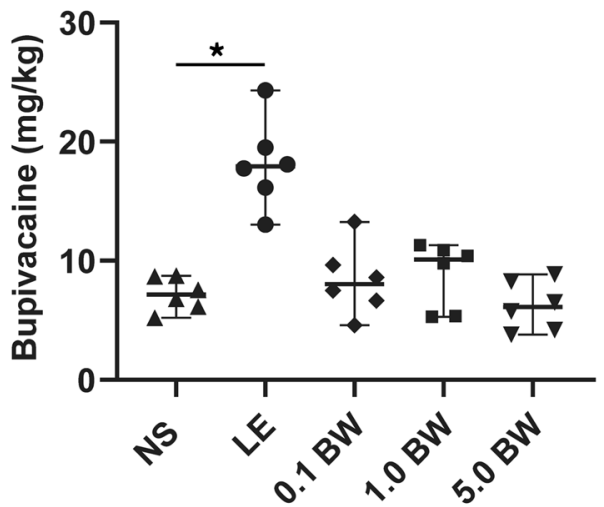

(d) Asystole

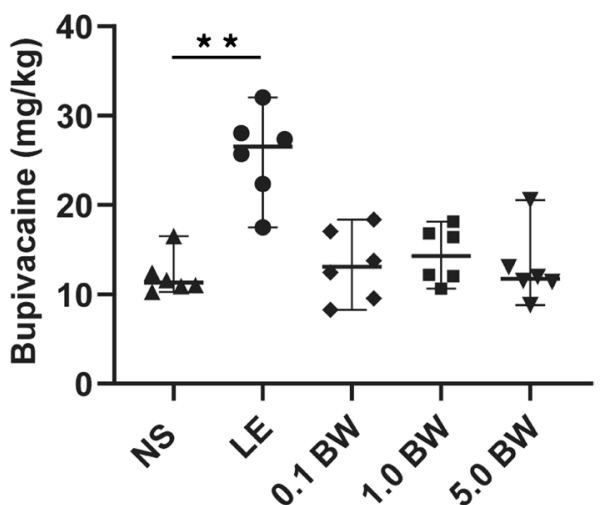

Fig. 2 The bupivacaine threshold of different cardiotoxic endpoints: a arrhythmia; b 50\% MAP-reduction; c 50\% HR-reduction; d asystole. Differences were found between group NS and LE in the bupivacaine dose of 50\% MAP-reduction, 50\% HR-reduction, and asystole. Abbreviations: NS normal saline, LE lipid emulsion, BW BW373U86, the agonist of delta-opioid receptor, MAP mean arterial pressure, $H R$ heart rate. $p<0.05$, ${ }^{* *} p<0.01, \stackrel{* * *}{p} p<0.001$

group LE and group NS on the arrhythmia dose of bupivacaine $(9.9[8.9-11.7]$ versus $5.6[4.5-7.0], p=0.060)$.

\section{Discussion}

The cardioprotective effects of DOR in ischemia/reperfusion and heart failure have long been highlighted in both in vivo and in vitro studies $[8,10,18,19]$, while the effect of DOR agonist on the cardiotoxicity of local anesthetics has never been explored before. Our study firstly investigated the effect of DOR agonist on the cardiotoxicity of bupivacaine in rats, however, we didn't observe any positive effect.

DOR is widely expressed in human and rodent myocardium and has been proved to involve in the cardioprotective and neuroprotective procedures in myocardial ischemia/reperfusion $[8,9,13,19,20]$. The mechanisms of DOR protective effects on the myocardium include triggering PKC, ERK1/2, Akt/PIK3, and other pathways.
These activated pathways may confer protection through regulating anti-apoptotic and autophagy elements, releasing $\mathrm{NO}$, inhibiting $\mathrm{Ca}^{2+}$ overload, phosphorylating GSK3 $\beta$, inhibiting mitochondrial permeability transition pore (mPTP) open [21], and activating mitochondrial $\mathrm{K}_{\text {ATP }}[7,22]$, of which mitochondrial function is closely involved. Both Furado et al. [21] and Bell et al. [19] reported that the contraction of human atrial trabeculae after ischemia/reperfusion is significantly increased with Delta 2 opioid D-Ala2-Leu5 enkephalin (DADLE, a DOR agonist) treatment. And the protective effect of DADLE is mediated by both the MPTP opener and mitochondrial $\mathrm{K}_{\text {ATP }}$ channel ( $\left.\mathrm{mK}_{\text {ATP }}\right)$.

It has been proved that bupivacaine exerts an adverse effect on the myocardium by inhibiting ion channels open (including sodium, potassium, and calcium channels) and disturbing mitochondrial energy metabolism [23, 24]. Chen $\mathrm{Y}$ et al. [25] reported that ropivacaine 
injuries human neuron $\mathrm{SH}-5 \mathrm{Y} 5 \mathrm{Y}$ through opening $\mathrm{mPTP}$, decreasing ATP production and inducing other mitochondrial dysfunctions. Thus, we hypothesized that DOR may protect the myocardium against bupivacaine by modulating mitochondrial function. However, we didn't observe any protective effects of DOR on the cardiotoxicity of bupivacaine in rats.

We chose $0.1,1.0$, and $5.0 \mathrm{mg} / \mathrm{kg}$ BW373U86, which is the low, median, and high doses of BW that have been proved to activate DOR in rats [13-16]. Therefore, we think it's sufficient to conclude that BW does not affect the cardiotoxicity of bupivacaine. This result seems contradictory to that of Partownavid et al. [6]. Partownavid et al. reported that DOR antagonists can abolish the therapeutic effect of LE against bupivacaine toxicity, which indicates that LE may exert protective effects by activating DOR. The reason for the difference may be due to the complex mechanism of LE rescuing LAST. DOR may only play an important role in it. However, it's not enough to ameliorate the toxicity of local anesthetics by activating DOR alone.

Unlike the 20\% LE that is used mostly, we used 30\% LE. Because $30 \%$ LE has been proved to exert cardioprotective effects against LAST as well [4], and the ratio of the main effective ingredients of $30 \% \mathrm{LE}$ to that of $20 \% \mathrm{LE}$ is 2:3. Thus we chose $2 \mathrm{ml} \cdot \mathrm{kg}^{-1} \cdot \mathrm{min}^{-1} 30 \% \mathrm{LE}$ following the dose of LE used by Weinberg and other researchers [4, $26,27]$.

The median doses of bupivacaine producing asystole in group NS and group LE of our study are $11.3 \mathrm{mg} / \mathrm{kg}$ and $26.5 \mathrm{mg} / \mathrm{kg}$ respectively. Both the two doses are lower than that of the study of Weinberg (group NS $17.7 \mathrm{mg} /$ $\mathrm{kg}$ and group LE $49.7 \mathrm{mg} / \mathrm{kg}$ ) [4]. We think this is mainly because we discontinued sevoflurane while Weinberg et al. did not. And inhale anesthetics, like sevoflurane and isoflurane, can prolong the death time of local anesthetics $[28,29]$. Because inhale anesthetics exert cardioprotective effects against LAST, thus we stopped sevoflurane as soon as finishing the invasive procedure and waited for 10-15 min to allow rats to exhale sevoflurane so that the result is more credible.

There are some limitations of our study. First, we just observed a phenomenon. This is mainly because the negative outcome limits further investigations on the mechanism. Second, we only studied the preventative effect without the resuscitative effect of DOR agonist on LAST. For lipid emulsion has been considered as the golden standard for the rescue of LAST, and we aimed to look for one drug that may help to prevent the cardiotoxicity of local anesthetics. Third, we didn't mirror expired $\mathrm{CO}_{2}$ concentration in this experiment, which may affect cardiac function. However, most of the literature we referred didn't mirror expired $\mathrm{CO}_{2}$ concentration, too. And the ventilator settings of our experiment are the same as those of others.

\section{Conclusions}

Our study demonstrates that BW373U86 does not affect the cardiotoxicity of bupivacaine in rats compared with normal saline control. $30 \%$ lipid emulsion can protect the myocardium against bupivacaine-induced cardiotoxicity.

\section{Abbreviations \\ NS: Normal saline; LE: Lipid emulsion; BW: BW373U86; ERAS: Enhanced recovery after surgery; MAP: Mean arterial pressure; HR: Heart rate; LAST: Local anesthetic systemic toxicity; ECG: Electrocardiogram; DADLE: Delta 2 opioid D-Ala2-Leu5 enkephalin; mPTP: mitochondrial permeability transition pore.}

\section{Acknowledgements}

We thank Dr. Yanqin Gao for providing the laboratory and rodent ventilator for this study. We are also grateful to Di Chen, Yiying Zhang, and Wei Li for their technical support and helpful discussion.

\section{Authors' contributions}

Methodology and Original draft preparation: CW; Methodology and Review: SS and JJ; Statistical analysis and Review: XY; Supervision, Resource, and Review: SH. All authors read and approved the final manuscript.

\section{Funding}

No funding is declared

\section{Availability of data and materials}

The datasets used and/or analyzed during the current study are available from the corresponding author on reasonable request.

\section{Declarations}

\section{Ethics approval and consent to participate}

This study was approved by the Animal Care and Use Committee of Fudan University on 16 March 2021 (ethic approval ID: 20210316-001) and performed according to the National Institutes of Health Guide for the Care and Use of Laboratory Animals. The study was carried out in compliance with the ARRIVE guidelines.

\section{Consent for publication}

Not applicable

\section{Competing interests}

The authors declare that they have no competing interests.

\section{Author details}

${ }^{1}$ Department of Anesthesia, Obstetrics \& Gynecology Hospital of Fudan University, Shanghai, China. ${ }^{2}$ Division of Epidemiology, Biostatistics and Environmental Health, Scholl of Health, University of Memphis, Memphis, USA.

Received: 18 July 2021 Accepted: 4 January 2022

Published online: 12 January 2022

\section{References}

1. Dickerson DM, Apfelbaum JL. Local anesthetic systemic toxicity. Aesthet Surg J. 2014;34(7):1111-9.

2. Liu L, Jin Z, Cai X, Xia Y, Zhang M, Papadimos TJ, Xu X, Shi K. Comparative Regimens of Lipid Rescue From Bupivacaine-Induced Asystole in a Rat Model. Anesth Analg. 2019;128(2):256-63.

3. Ok SH, Hong JM, Lee SH, Sohn JT. Lipid Emulsion for Treating Local Anesthetic Systemic Toxicity. Int J Med Sci. 2018;15(7):713-22. 
4. Weinberg GL, VadeBoncouer T, Ramaraju GA, Garcia-Amaro MF, Cwik MJ. Pretreatment or resuscitation with a lipid infusion shifts the doseresponse to bupivacaine-induced asystole in rats. Anesthsiology. 1998;88(4):1071-5.

5. Mather LE, Copeland SE. MVetClinStud, Ladd LA: Acute toxicity of local anesthetics underlying pharmacokinetic and pharmacodynamic concepts. Reg Anesth Pain Med. 2005;30(6):553-66.

6. Partownavid P, Sharma S, Li J, Umar S, Rahman S, Eghbali M. Involvement of Opioid Receptors in the Lipid Rescue of Bupivacaine-Induced Cardiotoxicity. Anesth Analg. 2015;121(2):340-7.

7. See Hoe L, Patel HH, Peart JN. Delta Opioid Receptors and Cardioprotection. Handb Exp Pharmacol. 2018;247:301-34.

8. Patel HH, Hsu A, Moore J, Gross GJ. BW373U86, a delta opioid agonist, partially mediates delayed cardioprotection via a free radical mechanism that is independent of opioid receptor stimulation. J Mol Cell Cardiol. 2001:33(8):1455-65

9. Pan L, Zhang Y, He Y, Chen Z, Wang S, Xia Y, Papadimos TJ, Lin W, Xu X. Dexmedetomidine elevates the lethal dose threshold of bupivacaine in rats: A dosing study. Hum Exp Toxicol. 2020;39(3):365-73.

10. Treskatsch S, Feldheiser A, Shaqura M, Dehe L, Habazettl H, Ropke TK, Shakibaei M, Schafer M, Spies CD, Mousa SA. Cellular localization and adaptive changes of the cardiac delta opioid receptor system in an experimental model of heart failure in rats. Heart Vessels. 2016;31(2):241-50.

11. Fu D, Liu H, Li S, Chen L, Yao J. Antioxidative and Antiapoptotic Effects of Delta-Opioid Peptide [D-Ala(2), D-Leu(5)] Enkephalin on Spinal Cord Ischemia-Reperfusion Injury in Rabbits. Front Neurosci. 2017;11:603.

12. Luo M, Yun X, Chen C, Bao N, Feng X, Pan L, Jin Z, Wu C, Wang X, Papadimos TJ, et al. Giving Priority to Lipid Administration Can Reduce Lung Injury Caused by Epinephrine in Bupivacaine-Induced Cardiac Depression. Reg Anesth Pain Med. 2016;41(4):469-76.

13. Yang $L$, Zhao X, Sun M, Sun X, Yao L, Yu D, Ding Q, Gao C, Chai W. Delta opioid receptor agonist BW373U86 attenuates post-resuscitation brain injury in a rat model of asphyxial cardiac arrest. Resuscitation. 2014;85(2):299-305

14. Shinmura K, Nagai M, Tamaki K, Bolli R. Gender and aging do not impair opioid-induced late preconditioning in rats. Basic Res Cardiol. 2004:99(1):46-55.

15. Patel HH, Ludwig LM, Fryer RM, Hsu AK, Warltier DC, Gross GJ. Delta opioid agonists and volatile anesthetics facilitate cardioprotection via potentiation of K(ATP) channel opening. Faseb j. 2002;16(11):1468-70.

16. Patel HH, Hsu AK, Gross GJ. COX-2 and iNOS in opioid-induced delayed cardioprotection in the intact rat. Life Sci. 2004;75(2):129-40.

17. Piskin O, Ayoglu H. Effects of Remifentanil Pretreatment on Bupivacaine Cardiotoxicity in Rats. Cardiovasc Toxicol. 2018;18(1):56-62.

18. Funcke S, Werner TR, Hein M, Ulmer BM, Hansen A, Eschenhagen T, Hirt MN. Effects of the Delta Opioid Receptor Agonist DADLE in a Novel Hypoxia-Reoxygenation Model on Human and Rat-Engineered Heart Tissue: A Pilot Study. Biomolecules. 2020;10(9):1309.

19. Bell SP, Sack MN, Patel A, Opie LH, Yellon DM. Delta opioid receptor stimulation mimics ischemic preconditioning in human heart muscle. J Am Coll Cardiol. 2000;36(7):2296-302.

20. Maslov LN, Oeltgen PR, Lishmanov YB, Brown SA, Barzakh El, Krylatov AV Pei JM. Activation of peripheral delta opioid receptors increases cardiac tolerance to arrhythmogenic effect of ischemia/reperfusion. Acad Emerg Med. 2014;21(1):31-9.

21. Fuardo M, Lemoine S, Lo Coco C, Hanouz JL, Massetti M. [D-Ala2, D-Leu5]-enkephalin (DADLE) and morphine-induced postconditioning by inhibition of mitochondrial permeability transition pore, in human myocardium. Exp Biol Med (Maywood). 2013;238(4):426-32.

22. LV MR, Li B, Wang MG, Meng FG, Yu JJ, Guo F, Li Y. Activation of the PI3KAkt pathway promotes neuroprotection of the delta-opioid receptor agonist against cerebral ischemia-reperfusion injury in rat models. Biomed Pharmacother. 2017:93:230-7.

23. Sztark F, Malgat M, Dabadie P, Mazat JP. Comparison of the effects of bupivacaine and ropivacaine on heart cell mitochondrial bioenergetics. Anesthesiology. 1998;88(5):1340-9.

24. Sztark F, Tueux O, Erny P, Dabadie P, Mazat JP. Effects of bupivacaine on cellular oxygen consumption and adenine nucleotide metabolism. Anesth Analg. 1994;78(2):335-9.
25. Chen $Y$, Yan $L$, Zhang $Y$, Yang $X$. The role of DRP1 in ropivacaine-induced mitochondrial dysfunction and neurotoxicity. Artif Cells Nanomed Biotechnol. 2019;47(1):1788-96.

26. Oda Y, Ikeda Y. Effect of lipid emulsion on the central nervous system and cardiac toxicity of bupivacaine and levobupivacaine in awake rats. J Anesth. 2013;27(4):500-4.

27. Hanci V, Karakaya K, Yurtlu S, Hakimoğlu S, Can M, Ayoğlu H, Erdoğan G, Okyay RD, Turan IO. Effects of dexmedetomidine pretreatment on bupivacaine cardiotoxicity in rats. Reg Anesth Pain Med. 2009;34(6):565-8.

28. Fukuda H, Hirabayashi Y, Shimizu R, Saitoh K, Mitsuhata H. Sevoflurane is equivalent to isoflurane for attenuating bupivacaine-induced arrhythmias and seizures in rats. Anesth Analg. 1996:83(3):570-3.

29. Tanaka K, Ludwig LM, Kersten JR, Pagel PS, Warltier DC. Mechanisms of cardioprotection by volatile anesthetics. Anesthesiology. 2004;100(3):707-21.

\section{Publisher's Note}

Springer Nature remains neutral with regard to jurisdictional claims in published maps and institutional affiliations.

Ready to submit your research? Choose BMC and benefit from

- fast, convenient online submission

- thorough peer review by experienced researchers in your field

- rapid publication on acceptance

- support for research data, including large and complex data types

- gold Open Access which fosters wider collaboration and increased citations

- maximum visibility for your research: over $100 \mathrm{M}$ website views per year

At BMC, research is always in progress.

Learn more biomedcentral.com/submissions 